\title{
The Effect of Doped Indium on the Electrical and Optical Properties of $\left(\mathrm{Se}_{0.7} \mathrm{Te}_{0.3}\right)_{1-\mathrm{x}} \mathrm{In} \mathrm{n}_{\mathrm{x}}$ Thin Films
}

\author{
Muhaj Talib Abdullah, Alan S. Said Ahmad, Ari A. Mohammed \\ Department of Physics, Faculty of Science, University of Zakho, Duhok, Iraq \\ Email: alho.amedi@yahoo.com
}

Received 12 March 2015; accepted 20 April 2015; published 22 April 2015

Copyright (C) 2015 by authors and Scientific Research Publishing Inc.

This work is licensed under the Creative Commons Attribution International License (CC BY). http://creativecommons.org/licenses/by/4.0/ c) (i) Open Access

\begin{abstract}
In-doped $\left(\mathrm{Se}_{0.7} \mathrm{Te}_{0.3}\right)$ thin films (In: $0,0.05$, and $\left.0.08 \mathrm{wt} \%\right)$ with thickness of $(150 \pm 25 \mathrm{~nm}$ ) have been deposited on glass substrates by chemical vapor deposition by using selenium, tellurium and indium whose purity is $(\mathbf{9 9 . 9 9 \% )}$ ) compound alloy. The electrical and optical properties of the thin films were analyzed. The effects of In-doping concentration on the thermoelectric properties of the thin films were investigated by room-temperature measurement of the See beck coefficient and electrical resistivity. The thermoelectric power factor shows the best result at $0.05 \mathrm{wt} \%$ in doping. The See beck coefficients are positive with increasing in doping concentration from 0 to $0.08 w t \%$. And the thin films show p-type conduction. For optical properties, the transmission of all samples was approximated to $90 \%$.
\end{abstract}

\section{Keywords}

Selenium, Tellurium, Indium, p-Type, Fermi-Level

\section{Introduction}

A chalcogenide glass is the glass containing a large amount of chalcogen atoms, i.e. $\mathrm{S}, \mathrm{Se}$, and Te, and a variety of compounds have been synthesized so far. Glasses can be characterized as covalent, metallic, and ionic. In covalent chalcogenide glasses such as Se and $\mathrm{As}_{2} \mathrm{~S}_{3}$, the so-called 8-N rule applies to the coordination number of constituent atoms, e.g. the coordination number of chalcogen is 2 . The band gap is $(2-3) \mathrm{eV}$, and electrical conduction in many materials is governed by holes. Accordingly, these glasses can be regarded as amorphous semiconductors [1]. The chalcogenide glasses show the quasi-continuous distribution of localized states in the forbidden gap which arise due to structural disorder in non-crystalline solids, which generates peculiarities of 
electronic processes, in particular, in transport, in optical and photoelectric processes. While the crystals having rigid structures do not permit removing of atoms from their fixed position in the network, the chalcogenide glasses, as well as other disordered materials having a more mobile structure, allow for changing the position of neighboring atoms under very small energetic influences by means of optical, X-ray radiation or electron beam [2].

The recent structural study on selenium and its alloys favor a "random chain model", in which all the atoms are in a twofold coordinated chain structure and not random. The dihedral angle $(\varphi)$, which is defined as the angle between two adjacent bonding planes as illustrated in Figure 1, is constant in magnitude but changes in sign randomly [3].

The doping of admixtures also leads to the change of molecular structure of glassy selenium. This is why admixtures in selenium are usually divided into three groups in accordance with their influence on the structure: isoelectron admixtures (oxygen, sulfur, and tellurium), branching admixtures (elements of the fourth and fifth groups) and univalent admixtures (hydrogen, alkaline metals, and thallium). Similar construction of the outermost electron shell of atoms of the sixth group most likely excludes the formation of new structural units under doping of selenium by isoelectron admixtures. It has been found that $\mathrm{Te}$ in $\mathrm{Se}-\mathrm{Te}$ glasses breaks up the $\mathrm{Se}_{8}$ ring structure and slightly increases the chain fraction but reduces the chain length. Se and Te have the function of forming the network of the glass and the strong decrease in the level of chain molecule polymerization. The decrease in the degree of polymerization leads to a decrease in crystallization activation energy of selenium with admixture of tellurium. The lower potential of tellurium atom ionization promotes the expansion of the photoconductivity spectrum of doped selenium in a long wave field. Resistivity and activation energy of selenium decreases with the growth of tellurium concentration [3]. In this paper we report the preparation of $\left(\mathrm{Se}_{0.7} \mathrm{Te}_{0.3}\right)_{1-\mathrm{x}} \mathrm{In}_{\mathrm{x}}$ compound thin films CVD technique and the structural, electrical and optical properties of the deposited films.

\section{Experimental Work}

We got that $\left(\mathrm{Se}_{0.7} \mathrm{Te}_{0.3}\right)_{1-\mathrm{x}} \mathrm{In}_{\mathrm{x}}$ compound was synthesized as an alloy by using Selenium, Tellurium and Indium whose impurity is $(99.99 \%)$ and then weighting each element according to the atomic weight $(\mathrm{Se}=78.96),(\mathrm{Te}=$

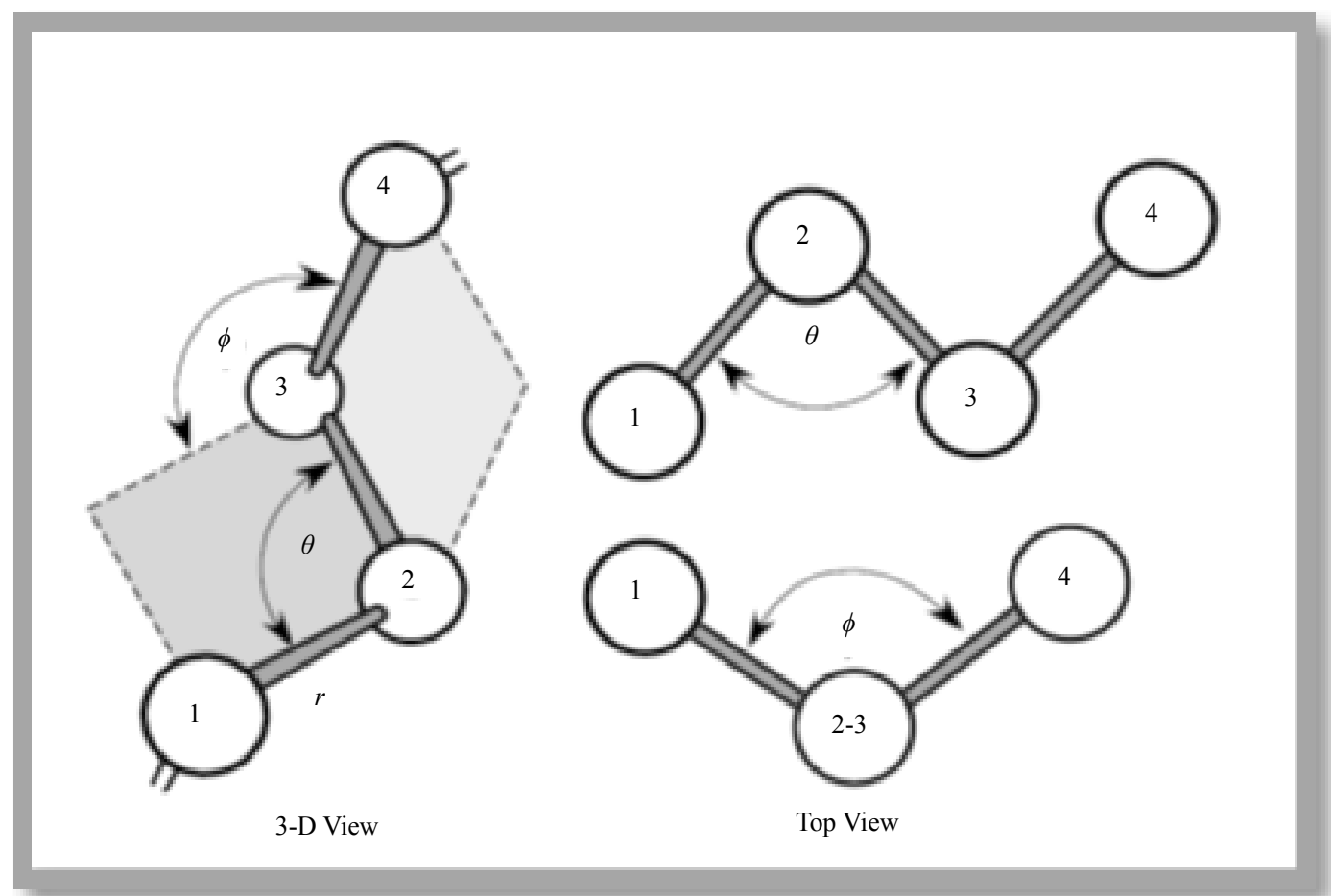

Figure 1. $a$-Se chain molecules and the definition of the dihedral angle. The dihedral angle is defined as the angle $(\varphi)$ between two adjacent bonding planes. It is observed looking down the bond joining atoms $2 \& 3$ just like the diagram on the right [3]. 
127.6) and ( $\mathrm{In}=114.818)$ by using sensitive electrical balance type (AE 166 Metter), then mixing these elements. Quartz tube is carefully cleaned in order to remove dust, grease and other possible contaminants, then putting this mixture in it (height of the tube equals to $10 \mathrm{~cm}$ and diameter equal $15 \mathrm{~mm}$ ) which is evacuated until pressure reached $\approx\left(10^{-2}\right.$ Torr $)$, the tube is sealed and put in electric furnace of type SRJX-5-13 Model Box-Resistance Furnace Control Box by (Tianjin Taisite instrument co. LTD) and the ampoules containing material were heated to $600^{\circ} \mathrm{C}$, which is above the melting point of $\mathrm{Se}\left(220.5^{\circ} \mathrm{C}\right)$. Te $\left(449.51^{\circ} \mathrm{C}\right)$ as shown in Figure 2 and $\operatorname{In}\left(156.60^{\circ} \mathrm{C}\right)$ and were held at $600^{\circ} \mathrm{C}$ for $4-5 \mathrm{~h}$. The temperature of the furnace was raised slowly at a rate of $3^{\circ} \mathrm{C}-4^{\circ} \mathrm{C} / \mathrm{min}$.

The quartz ampoules were constantly rocked. This was done to obtain homogeneous glassy alloys, after that the ampoule was taken out, and cooled rapidly in cold water to reduce segregation and to obtain more homogenous alloy. The quenched samples were then taken out by breaking the quartz ampoules. $\left(\mathrm{Se}_{0.7} \mathrm{Te}_{0.3}\right)_{1-\mathrm{x}} \mathrm{In}_{\mathrm{x}}$ thin films deposited on glass substrates, made in Germany from "Objekttrager Factory", have dimension $(76 \times 26 \times$ $\left.1.5 \mathrm{~mm}^{3}\right)$.

\section{Results and Discussion}

\subsection{Structural Measurements}

The structure of the $\left(\mathrm{Se}_{0.7} \mathrm{Te}_{0.3}\right)_{1-\mathrm{x}} \mathrm{In}_{\mathrm{x}}$ alloys have been examined by XRD methods using (Shimad $\mathrm{Zu} 6000$ ) made in Japan, with the following specifications:

\subsection{XRD}

Target: Cu $\alpha$, Wavelength: 1.5406 A, Current: 30 (mA.), Voltage: 40 (KV)

Doping with Indium in $\left(\mathrm{Se}_{0.7} \mathrm{Te}_{0.3}\right)_{1-\mathrm{x}} \mathrm{In}$ thin films, the structure remained amorphous for $\left(\mathrm{Se}_{0.7} \mathrm{Te}_{0.3}\right)_{0.95} \mathrm{In}_{0.05}$, $\left(\mathrm{Se}_{0.7} \mathrm{Te}_{0.3}\right)_{0.92} \mathrm{In}_{0.08}$ composition. No peaks, characteristic to the crystalline phase, were detected in the obtained patterns and hence confirming the amorphous nature of the prepared samples as shown in Figure 3. This amorphous structure shows agreements with previous experiments [1] [5].

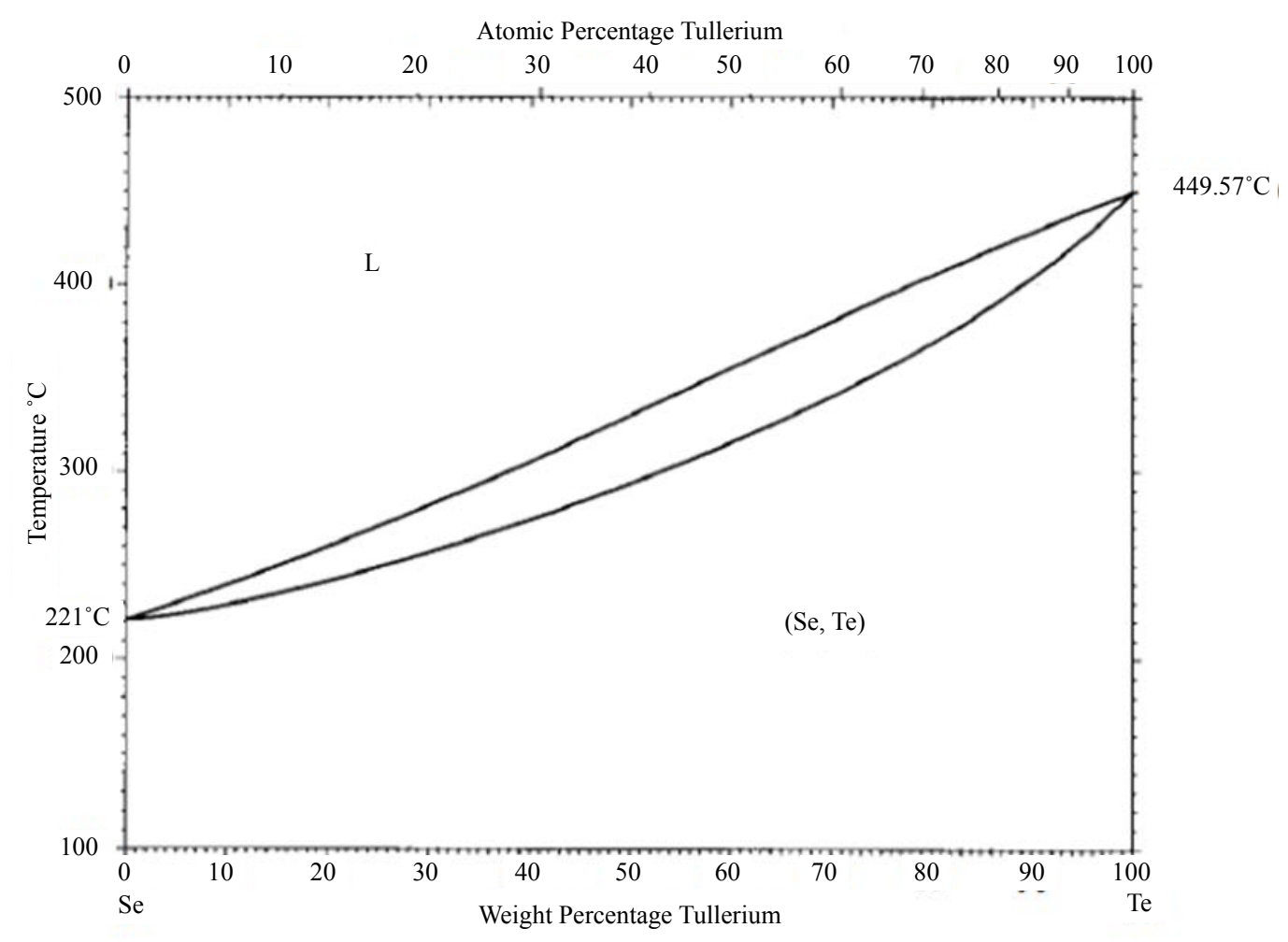

Figure 2. Alloy phase diagram for Se-Te alloy [4]. 


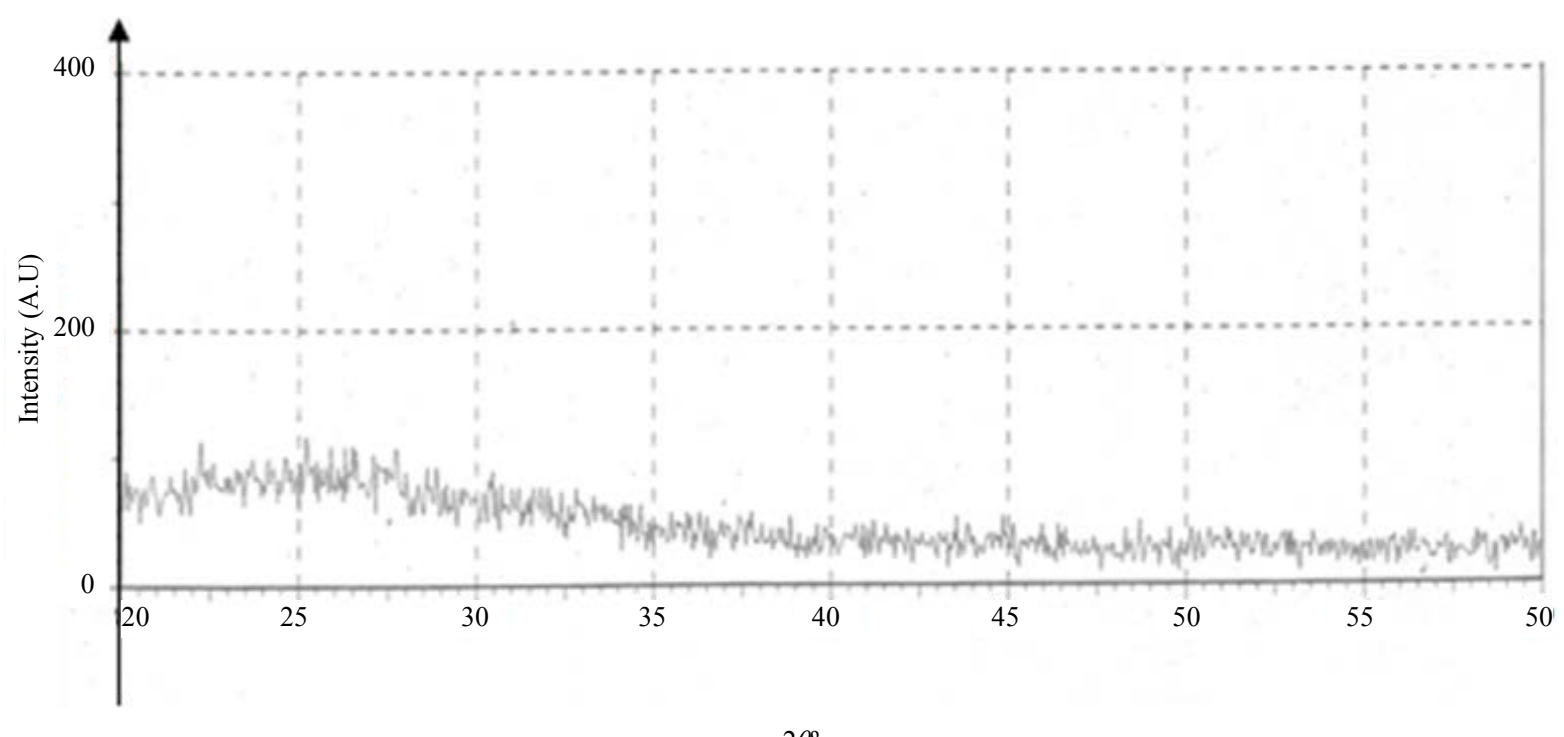

(a)

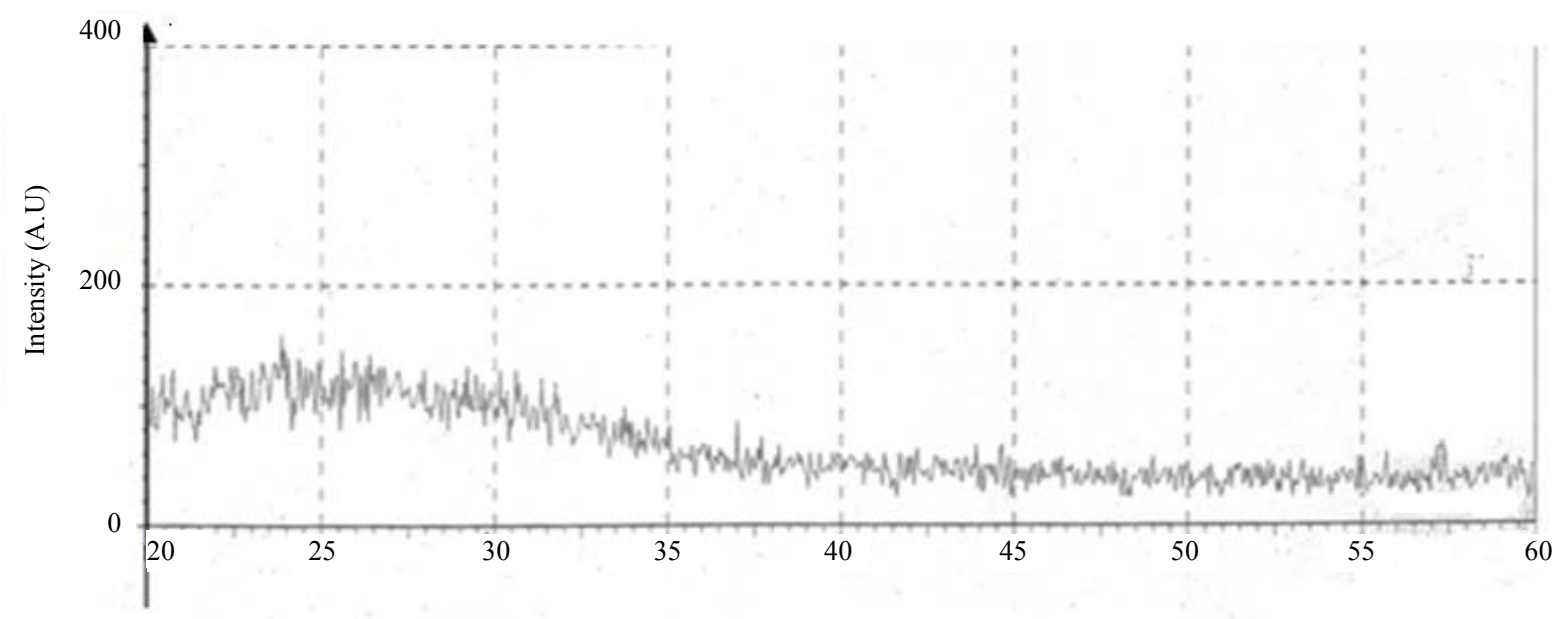

$2 \theta^{\circ}$

(b)

Figure 3. (a) XRD pattern of $\left(\mathrm{Se}_{0.7} \mathrm{Te}_{0.3}\right)_{0.95} \mathrm{In}_{0.05}$ thin films with thickness $(150 \pm 25 \mathrm{~nm})$ deposited at R.T. (b) XRD pattern of $\left(\mathrm{Se}_{0.7} \mathrm{Te}_{0.3}\right)_{0.92} \mathrm{In}_{0.08}$ thin films with thickness $(150 \pm 25 \mathrm{~nm})$ deposited at R.T.

\subsection{The Electrical Measurements}

The electrical properties, by combined measurements of D.C conductivity, thermoelectric power, current-voltage characteristics and intensity dependence of photoconductivity, have been studied to yield valuable information about the transport mechanism of the charge carriers and the type of charge carriers in $\left(\mathrm{Se}_{0.7} \mathrm{Te}_{0.3}\right)_{1-\mathrm{x}} \mathrm{In}_{\mathrm{x}}$ thin films. Furthermore, the influence of doping Indium on the electrical properties of $\left(\mathrm{Se}_{0.7} \mathrm{Te}_{0.3}\right)_{1-\mathrm{x}} \mathrm{In}_{\mathrm{x}}$ thin films.

\subsection{1. (I-V) Measurements}

A study of $\mathrm{I}-\mathrm{V}$ characteristics is a matter of importance for property analyzing the conduction mechanism in thin films. The increases in voltage help to transfer electrons from valance band to conduction band and increasing conduction electrons and therefore increase current [6]. We showed that in Figure 4 the (I-V) characteristics for $\left(\mathrm{Se}_{0.7} \mathrm{Te}_{0.3}\right)_{1-\mathrm{x}} \mathrm{In}_{\mathrm{x}}(\mathrm{x}=0,0.05,0.08)$ thin films in the same conditions and current increase linearly with increasing voltage in ohmic behavior. 
It can be observed that current increase with increasing Indium concentration at the same voltage range. Incorporation of third element (In) to Se-Te alloy is expected to modify the structure of the host alloy, with the new element entering into chemical bond formation. The addition of (In) will induce more and more positively charged localized states, as the electron affinity of In is much lower than that of Se and Te. Therefore, an increase in defect states with increasing Indium concentration may be understood in terms of very low electron affinity of (In) $(0.30 \mathrm{eV})$ as compared to Se or Te [7] [8].

\subsubsection{D.C Conductivity Measurements}

The D.C conductivity for $\left(\mathrm{Se}_{0.7} \mathrm{Te}_{0.3}\right)_{1-\mathrm{x}} \mathrm{In}_{\mathrm{x}}(\mathrm{x}=0.05,0.08)$ thin films have been studied as a function of temperature with thickness $(150 \pm 25 \mathrm{~nm})$ within the range $(293-423) \mathrm{K}$.

In Figure 5, the variation of $\ln \sigma_{d . c}$ with $1000 / \mathrm{T}$ for $\left(\mathrm{Se}_{0.7} \mathrm{Te}_{0.3}\right)_{1-\mathrm{x}} \mathrm{In}_{\mathrm{x}}(\mathrm{x}=0.05,0.08)$ thin films, it can noticed that the conduction in these thin films having single activation energy within the range (293 - 423) K.

The conductivity increases and activation energy decreases with increasing Indium concentration in $\left(\mathrm{Se}_{0.7} \mathrm{Te}_{0.3}\right)_{0.95} \mathrm{In}_{0.05}$ thin film then D.C conductivity decreases and activation energy increases in $\left(\mathrm{Se}_{0.7} \mathrm{Te}_{0.3}\right)_{0.92} \mathrm{In}_{0.08}$ thin film as seen in Figure 6 and Table 1.

The idea behind that is incorporation of Indium in Se-Te binary Se-Te-In ternary system and give it more metallic character due to (In) concentration. Due to addition of Indium concentration in ternary system, the structures are heavily cross-linked increases. Therefore, the expanse of Se chains and replacement of weak Se-Se bonds by (Se-In) bonds results in the increase and decrease in their associative electrical properties [9].

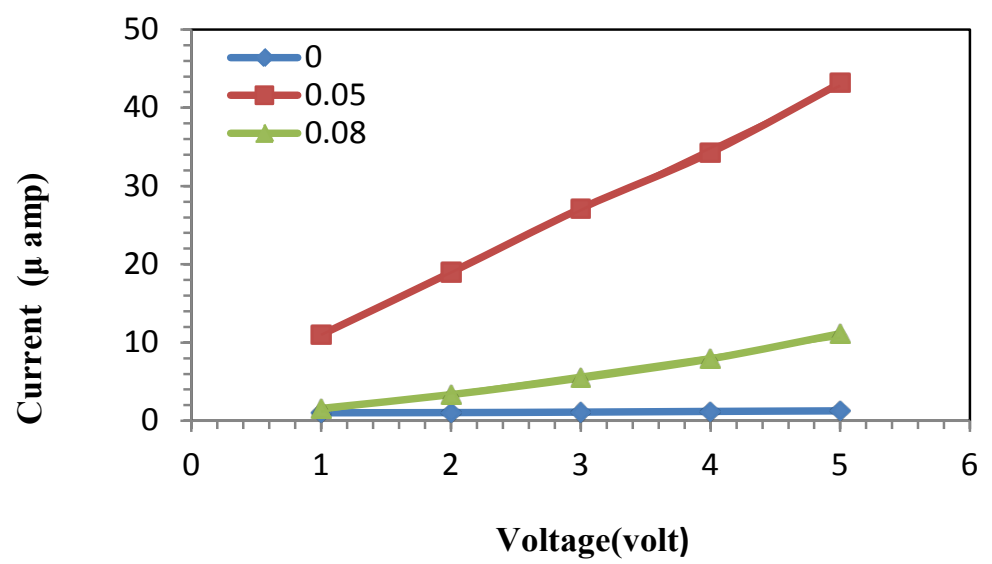

Figure 4. (I-V) characteristics for $\left(\mathrm{Se}_{0.7} \mathrm{Te}_{0.3}\right)_{1-\mathrm{x}} \mathrm{In}_{\mathrm{x}}(\mathrm{x}=0,0.05,0.08)$ thin films with thickness $(150 \pm 25 \mathrm{~nm})$ at R.T.

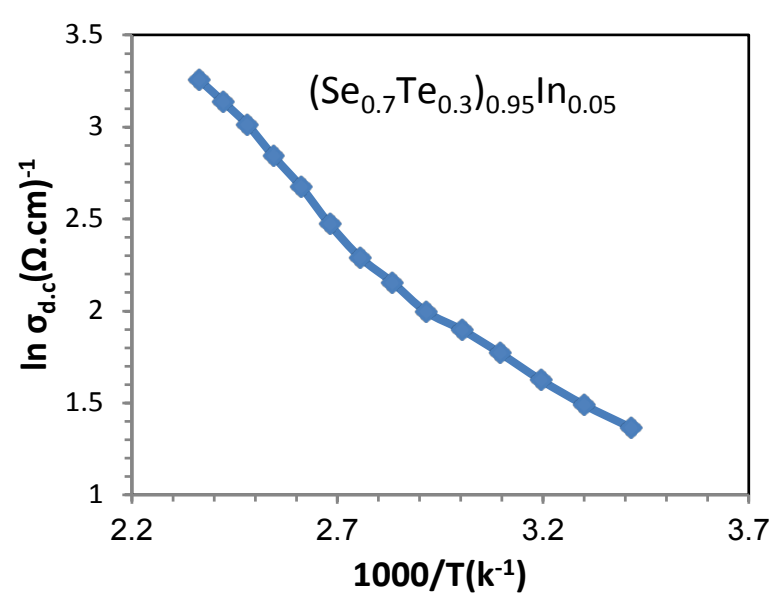

(a)

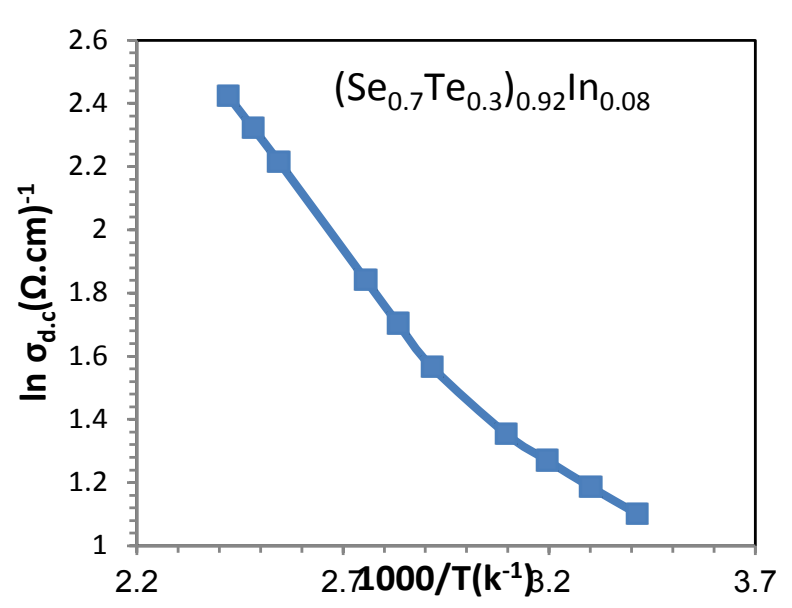

(b)

Figure 5. Temperature dependence of conductivity for $\left(\mathrm{Se}_{0.7} \mathrm{Te}_{0.3}\right)_{1-\mathrm{x}} \mathrm{In} \mathrm{x}_{\mathrm{x}}$ (a) $\left(\mathrm{Se}_{0.7} \mathrm{Te}_{0.3}\right)_{0.95} \mathrm{In}_{0.05}$ and (b) $\left(\mathrm{Se}_{0.7} \mathrm{Te}_{0.3}\right)_{0.92} \mathrm{In}_{0.08}$ with thickness $(150 \pm 25 \mathrm{~nm})$ at R.T. 
On $\left(\mathrm{Se}_{0.7} \mathrm{Te}_{0.3}\right)_{0.95} \mathrm{In}_{0.05}$ composition, glass structure becomes more chemically ordered and contains only strong Se-In bonds. Due to this, the maximum cross-linking has occurs which results larger number of defects in density of localized states. It might be reasonable to generate larger number of free electrons in density of localized states. Incorporation of (In) concentration beyond that atomic percentage in $\left(\mathrm{Se}_{0.7} \mathrm{Te}_{0.3}\right)_{0.92} \mathrm{In}_{0.08}$ probably reduces the Se-In bonds increases In-In bond strength in glassy structure, therefore decreases the defects bonds in density of localized state, result decrease in corresponding electrical properties of $\left(\mathrm{Se}_{0.7} \mathrm{Te}_{0.3}\right)_{1-\mathrm{x}} \mathrm{In}_{\mathrm{x}}$ thin films [10].

\subsubsection{Thermoelectric Power Measurements}

We have been plotted in Figure 7 that the temperature dependence of the thermo-electric power (S) for $\left(\mathrm{Se}_{0.7} \mathrm{Te}_{0.3}\right)_{1-\mathrm{x}} \mathrm{In}_{\mathrm{x}}(\mathrm{x}=0,0.05,0.08)$ thin films. It also can be noticed that (S) vs. 1000/T graphs are straight lines with a positive slope indicating that (S) decreases linearly with temperature and positive See beck coefficient indicated that holes is the predominate charge carriers.

In Figure 8, it represented the variation of $\left(E_{s}\right)$ with Indium content and it is obvious that $\left(E_{s}\right)$ increases with increasing (In) content in $\left(\mathrm{Se}_{0.7} \mathrm{Te}_{0.3}\right)_{0.95} \mathrm{In}_{0.05}$ composition then decreases in $\left(\mathrm{Se}_{0.7} \mathrm{Te}_{0.3}\right)_{0.92} \mathrm{In}_{0.08}$ composition.

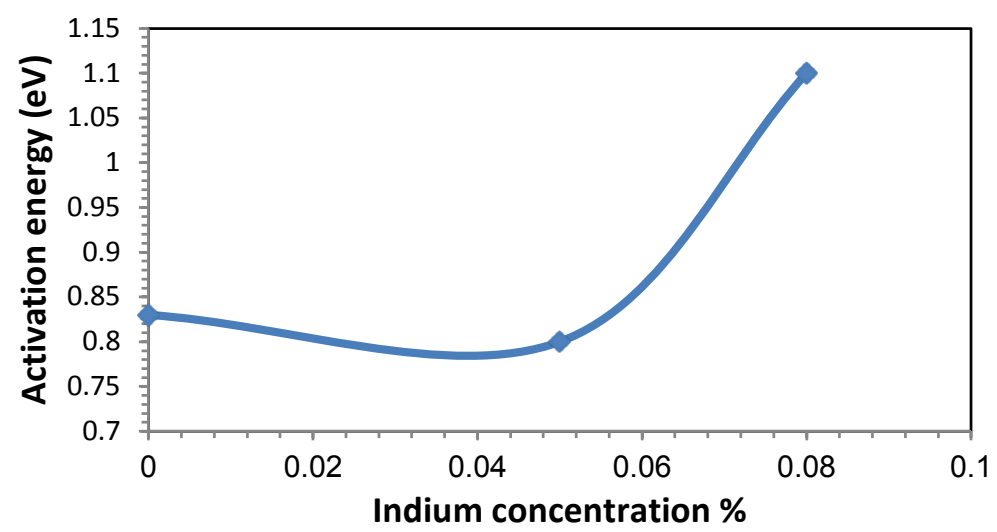

Figure 6. Variation of activation energy with Indium concentration $\left(\mathrm{Se}_{0.7} \mathrm{Te}_{0.3}\right)_{1-\mathrm{x}} \mathrm{In}_{\mathrm{x}}(\mathrm{x}=0$, $0.05,0.08)$ thin films with thickness $(150 \pm 25 \mathrm{~nm})$ at R.T.

Table 1. D.C conductivity and activation energy for $\mathrm{Se}_{1-\mathrm{x}} \mathrm{Te}_{\mathrm{x}},\left(\mathrm{Se}_{0.7} \mathrm{Te}_{0.3}\right)_{1-\mathrm{x}} \mathrm{In}_{\mathrm{x}}$ thin films.

\begin{tabular}{|c|c|c|c|}
\hline Composition & $\sigma_{d . c}(\Omega \cdot \mathbf{c m})^{-1}$ at $(293 \mathrm{~K})$ & $\sigma_{d . c}(\Omega \cdot \mathbf{c m})^{-1}$ at $(423 \mathrm{~K})$ & $E_{a}(\mathrm{eV})$ \\
\hline$\left(\mathbf{S e}_{0.7} \mathbf{T e}_{0.3}\right)_{0.95} \mathbf{I n}_{0.05}$ & 5.456 & 16.148 & 0.8 \\
\hline$\left(\mathbf{S e}_{0.7} \mathbf{T e}_{0.3}\right)_{0.92} \mathbf{I n}_{0.08}$ & 3.260 & 12.807 & 1.1 \\
\hline
\end{tabular}

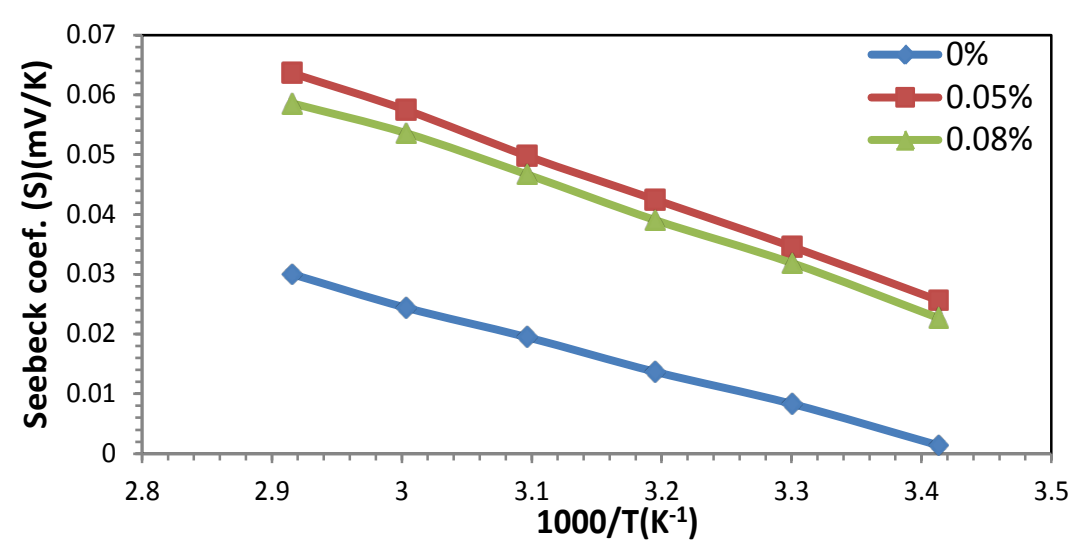

Figure 7. Temperature dependence of the thermoelectric power for $\left(\mathrm{Se}_{0.7} \mathrm{Te}_{0.3}\right)_{1-\mathrm{x}} \mathrm{In}_{\mathrm{x}}(\mathrm{x}=0$, $0.05,0.08)$ thin films with thickness $(150 \pm 25 \mathrm{~nm})$ at R.T. 
Figure 9 shows that conductivity is p-type for all investigated samples and Fermi-level lies below the midgap, which means that the conductivity has resulted from transport of the holes and the localized states at the valence edge are used in the process of conduction. This result is similar to the results observed by [10]. Table 2 represents the values of activation energy of thermoelectric power for $\left(\mathrm{Se}_{0.7} \mathrm{Te}_{0.3}\right)_{1-\mathrm{x}} \mathrm{In}_{\mathrm{x}}$ thin films.

\subsection{The Optical Measurements}

\subsubsection{Transmission Measurements}

The influence of Indium concentration in $\left(\mathrm{Se}_{0.7} \mathrm{Te}_{0.3}\right)_{1-\mathrm{x}} \mathrm{In}_{\mathrm{x}}(\mathrm{x}=0.05,0.08)$ thin films on the optical properties of the prepared films was studied extensively. Figure 10 illustrated the variation of wave transmission with the wave length in the range $(300-900 \mathrm{~nm})$ and from this figure it is clear that transmission increase with increasing wave length and decrease with increasing Indium concentration. $\mathrm{Se}_{0.7} \mathrm{Te}_{0.3}$ has the highest transmission comparing to all prepared samples.

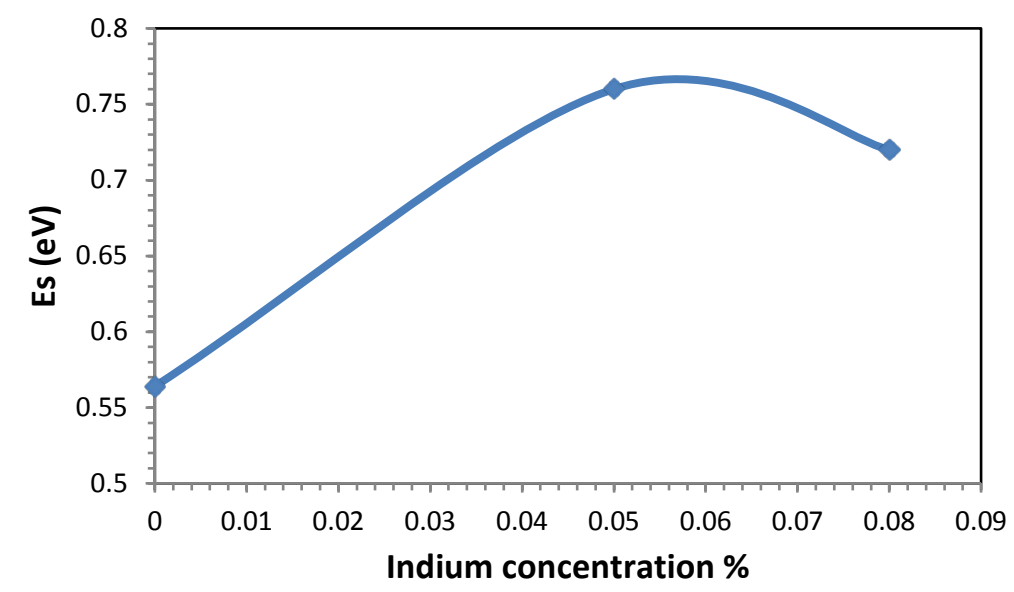

Figure 8. Variation of $\left(E_{s}\right)$ with Indium content in $\left(\mathrm{Se}_{0.7} \mathrm{Te}_{0.3}\right)_{1-\mathrm{x}} \mathrm{In}_{\mathrm{x}}(\mathrm{x}=0$, $0.05,0.08)$ thin films with thickness $(150 \pm 25 \mathrm{~nm})$ at R.T.

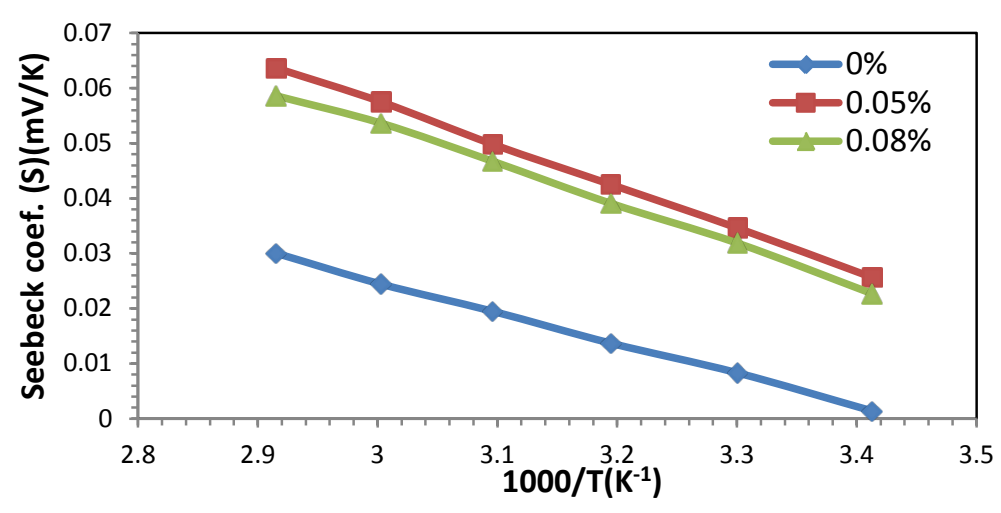

Figure 9. Temperature dependence of the thermoelectric power for $\left(\mathrm{Se}_{0.7} \mathrm{Te}_{0.3}\right)_{1-\mathrm{x}} \mathrm{In}_{\mathrm{x}}(\mathrm{x}=0,0.05,0.08)$ thin films with thickness $(150 \pm 25 \mathrm{~nm})$ at R.T.

Table 2. Represents $\left(E_{s}\right)$ for $\mathrm{Se}_{1-\mathrm{x}} \mathrm{Te}_{\mathrm{x}}$ and $\left(\mathrm{Se}_{0.7} \mathrm{Te}_{0.3}\right)_{1-\mathrm{x}} \mathrm{In}$ 的 thin films.

\begin{tabular}{cc}
\hline Composition & $\left(E_{s} \mathrm{eV}\right)$ \\
$\mathrm{Se}_{0.7} \mathrm{Te}_{0.3}$ & 0.56 \\
$\left(\mathrm{Se}_{0.7} \mathrm{Te}_{0.3}\right)_{0.95} \mathrm{In}_{0.05}$ & 0.76 \\
$\left(\mathrm{Se}_{0.7} \mathrm{Te}_{0.3}\right)_{0.92} \mathrm{In}_{0.08}$ & 0.72 \\
\hline
\end{tabular}




\subsubsection{Absorbance Measurements}

Figure 11 showed the variation of absorbance as a function with wave length for $\left(\mathrm{Se}_{0.7} \operatorname{Te}_{0.3}\right)_{1-\mathrm{x}} \mathrm{In}_{\mathrm{x}}(\mathrm{x}=0,0.05$, 0.08) thin films. From Figure 11, it is clear that absorption increase with increasing Indium concentration and have higher absorption at the visible spectrum.

\subsection{Optical Constants}

\subsubsection{Refractive Index}

Refractive index can be determined using equation

$$
n=\frac{1+\sqrt{R}}{1-\sqrt{R}}
$$

where $\mathrm{n}$ is the refractive index, $\mathrm{R}$ is the reflection of samples.

From Figure 12, the refractive index increased with increasing wave length from $(600 \mathrm{~nm})$ up to higher wave lengths, also refractive index (n) increased with increasing indium concentration because the addition of (In) atoms is incorporated in cross-linking the ( $\mathrm{Se}$ ) chains by bonding with $(\mathrm{Se})$ atoms. The increase in the refractive index may be described to increased polarizability of larger In-atoms (atomic radius $=167 \mathrm{pm}$ ) in comparison with Se (120) and Te (140) atoms. The large In-atoms may cause more polarization and the increase of refractive index in relation with polarizability [11].

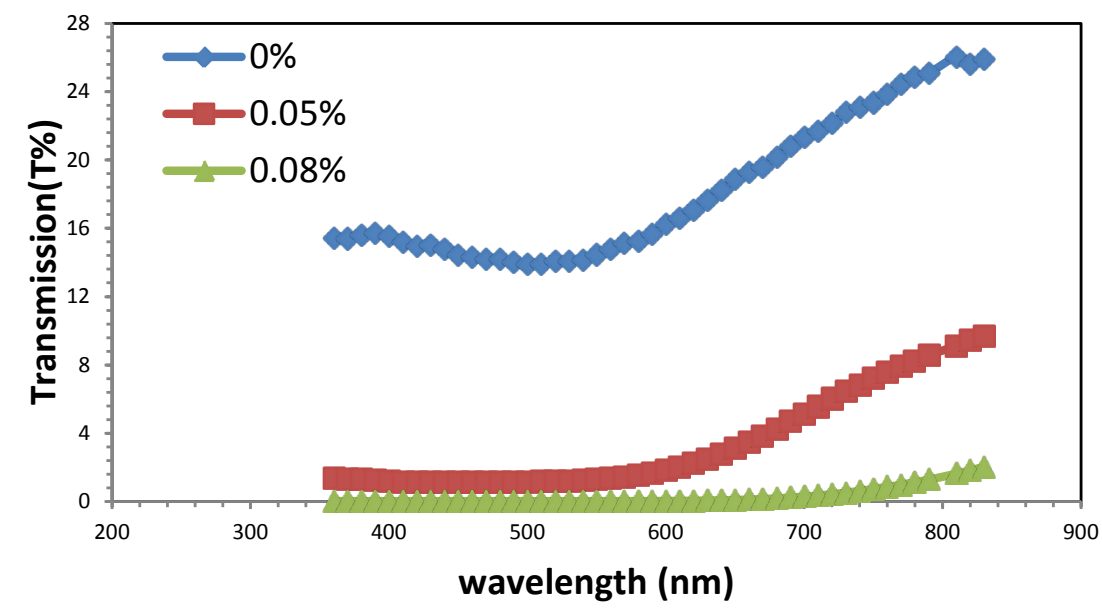

Figure 10. Shows transmission spectrum of $\left(\mathrm{Se}_{0.7} \mathrm{Te}_{0.3}\right)_{1-\mathrm{x}} \mathrm{In}_{\mathrm{x}}(\mathrm{x}=0,0.05,0.08)$ thin films with thickness $(150 \pm 25 \mathrm{~nm})$ at R.T.

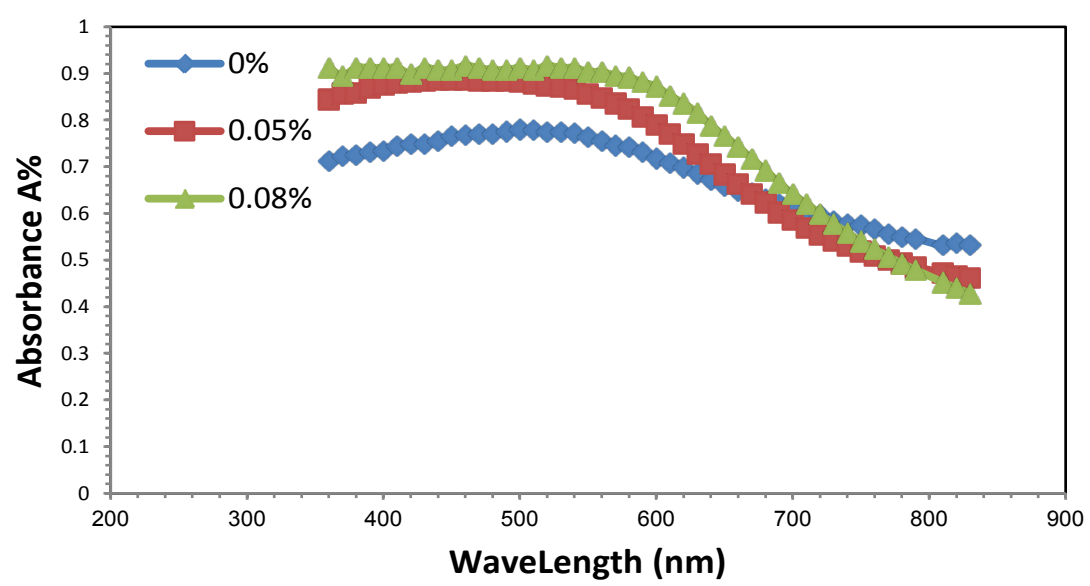

Figure 11. Absorbance spectrum of $\left(\mathrm{Se}_{0.7} \mathrm{Te}_{0.3}\right)_{1-\mathrm{x}} \mathrm{In}_{\mathrm{x}}(\mathrm{x}=0,0.05,0.08)$ thin film with thickness $(150 \pm 25 \mathrm{~nm})$ at R.T. 


\subsubsection{Dielectric Constant}

The complex dielectric constant is fundamental intrinsic material property. The real part of it is associated with the term that how much it will slow down the speed of light in the material and imaginary part gives that how a dielectric absorb energy from electric field due to dipole motion. The real and imaginary parts of the dielectric constant were determined using the relation [12]. Both real part and imaginary part of dielectric constant are measured for prepared films by using relations

$$
\begin{aligned}
& \varepsilon_{1}=n^{2}-k^{2} \\
& \varepsilon_{2}=2 \mathrm{nk}
\end{aligned}
$$

The values of $\left(\varepsilon_{1}\right),\left(\varepsilon_{2}\right)$ depend on refractive index (n) and extinction coefficient (k).

Figure 13 illustrated variation of $\left(\varepsilon_{1}\right)$ and $\left(\varepsilon_{2}\right)$ as a function of wavelength. It is observed that their values increase with wavelength at $(600 \mathrm{~nm})$ up to longer wave lengths and $\left(\varepsilon_{1}\right)$ and $\left(\varepsilon_{2}\right)$ values increase with increasing Indium concentration and are attributed to an increase in density of charged defect states and this result show a similar behavior of the previous experiments [13] [14].

\section{Conclusion}

By using the chemical vapor deposition technique, $\left(\mathrm{Se}_{0.7} \mathrm{Te}_{0.3}\right)_{1-\mathrm{x}} \mathrm{In} \mathrm{n}_{\mathrm{x}}(\mathrm{x}=0,0.05,0.08)$ thin films were prepared.

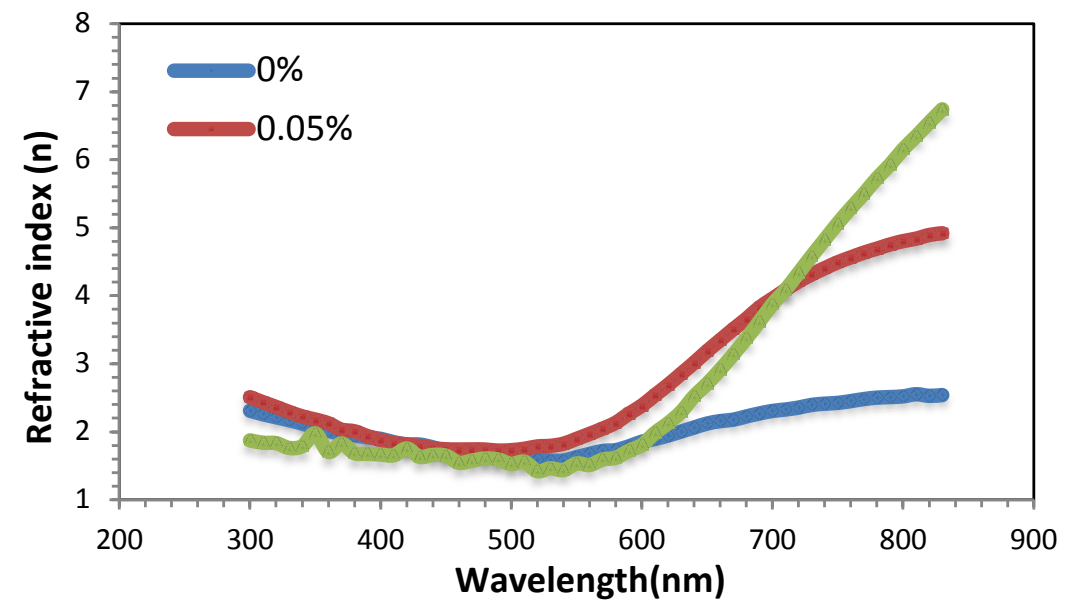

Figure 12. Variation of refractive index as a function with wave length for $\left(\mathrm{Se}_{0.7} \mathrm{Te}_{0.3}\right)_{1-\mathrm{x}} \mathrm{In}_{\mathrm{x}}(\mathrm{x}=0,0.05,0.08)$ thin films.

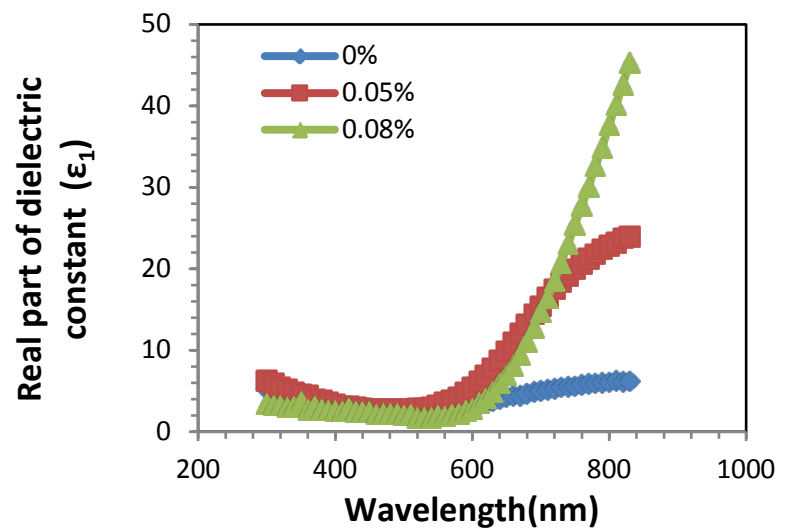

(a)

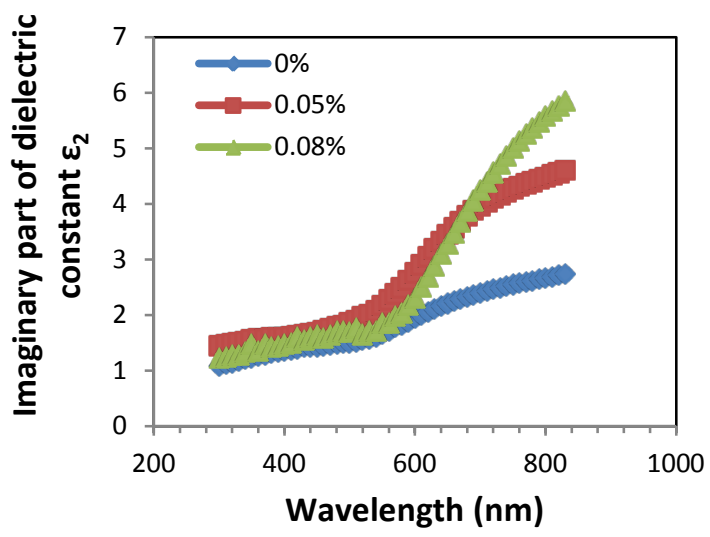

(b)

Figure 13. Variation of real part of dielectric constant $\left(\varepsilon_{1}\right)$ with wave length for $\left(\operatorname{Se}_{0.7} \operatorname{Te}_{0.3}\right)_{1-\mathrm{x}} \operatorname{In}_{\mathrm{x}}(\mathrm{x}=0,0.05,0.08)$ thin films with thickness $(150 \pm 25 \mathrm{~nm})$ at R.T. Variation of imaginary part of dielectric constant $\left(\varepsilon_{2}\right)$ with wave length for $\left(\mathrm{Se}_{0.7} \mathrm{Te}_{0.3}\right)_{1-\mathrm{x}} \operatorname{In}_{\mathrm{x}}(\mathrm{x}=0,0.05,0.08)$ thin films with thickness $(150 \pm 25 \mathrm{~nm})$ at R.T. 
The electrical and optical properties of films at different doping concentration were successfully measured. From (I-V) measurements can be observed that current increase with increasing indium concentration at the same voltage range, the conductivity increases and activation energy decreases with increasing indium concentration in $\left(\mathrm{Se}_{0.7} \mathrm{Te}_{0.3}\right)_{0.95} \mathrm{In}_{0.05}$ thin film then D.C conductivity decreases and activation energy increases in $\left(\mathrm{Se}_{0.7} \mathrm{Te}_{0.3}\right)_{0.92} \mathrm{In}_{0.08}$ thin film. Transmission and absorbance increased with increasing wave length and decreased with increasing indium concentration. So, from the obtained results, we find that doping with indium has improved the electrical and optical properties in $\left(\mathrm{Se}_{0.7} \mathrm{Te}_{0.3}\right)_{0.95} \mathrm{In}_{0.05}$ composition and then the properties start to retreat in $\left(\mathrm{Se}_{0.7} \mathrm{Te}_{0.3}\right)_{0.92} \mathrm{In}_{0.08}$ composition.

\section{References}

[1] Kolobov, A.V. (2003) Photo-Induced Meta Stability in Amorphous Semiconductors. Wiley-VCH GMB and Co. KGa. A.

[2] Andriesh, A.M., Iovu, M.S. and Shutov, S.D. (2002) Chalcogenide Non-Crystalline Semiconductors in Optoelectronics. Journal of Optoelectronics and Advanced Materials, 4, 631-647.

[3] Fairman, R. and Ushkov, B. (2004) Semiconducting Chalcogenide Glass I, Glass Formation, Structure, and Stimulated Transformations in Chalcogenide Glasses, Semiconductors and Semimetals. Vol. 78, Elsevier Academic Press.

[4] Baker, H. (1992) Alloy Phase Diagrams. Vol. 3, ASM International.

[5] Maged, A.F., Amin, G.A., Semarym M. and Borham, E. (2009) Some Physical Properties of $\mathrm{Se}_{0.8} \mathrm{Te}_{0.2} \mathrm{Amorphous}$ Chalcogenide System. Journal of Non-Oxide Glasses, 1, 53-60.

[6] Krishna, J., Kumar, D., Sarish, Y., Shukla, R.K. and Kumar, A. (2010) Light Induced Deffects in Amorphous Thin Films Of $\mathrm{Se}_{70} \mathrm{Te}_{28} \mathrm{Zn}_{2}$. Chalcogenide Letters, 7, 257-262.

[7] Maan, A.S., Goyal, D.R. and Kumar, A. (2007) Investigation of Optical Absorption in $\operatorname{Te}_{5}\left(\operatorname{In}_{\mathrm{x}} \operatorname{Se}_{100-\mathrm{x}}\right)_{95}$ Glassy Alloys. Chalcogenide Letters, 4, 48-53.

[8] Singh, R., Tripathi, S.K. and Kumar, S. (2008) Role of Cu Additive in the Density of Localized States in a-Ge $\mathrm{Ge}_{20} \mathrm{Se}_{80}$ Glassy Alloy. Indian Journal of Pure and Applied Physics, 46, 38-41.

[9] Singh, A.K., Mehta, N. and Singh, K. (2009) Electrical Properties of $\mathrm{Se}_{93-\mathrm{X}}-\mathrm{Zn}_{2}-\mathrm{Te}_{5}-\mathrm{In}_{\mathrm{X}}$ Chalcogenide Glasses. Chalcogenide Letters, 6, 9-14.

[10] Shurygin, P.M., Orlov, A.M. and Lebedev, Y.I. (1975) Effect of Selenium on the Thermoelectric Properties of Tellurium. M. I. Kalintn Institute of Nonferrous Metals, 25-29.

[11] Mainika, S.P., Katyal, S.C. and Thakur, N. (2009) A Study of Impurities (Ag, Bi \& Ge) on the Optical Properties of Se-Te Thin Films. Journal of Non-Oxide Glasses, 1, 90-95.

[12] Sharma, P., Sharma, V. and Katyal, S.C. (2006) Variation of Optical Constants in $\mathrm{Ge}_{10} \mathrm{Se}_{60} \mathrm{Te}_{30}$ Thin Film. Chalcogenide Letters, 3, 73-79.

[13] Abd El-Raheem, M.M., Abd Alghany, H.A., Wakkad, M.M, Abousehly, A.M. and Abd-Allah, N.A. (2009) Optical Properties of In-Ge-Se Thin Films. Chalcogenide Letters, 6, 35-44.

[14] Maan, A.S. and Goyal, D.R. (2008) Dielectric Properties of In-Se-Te Glassy Alloys. Indian Journal of Engineering and Material Sciences, 15, 207-221. 